\title{
Effect of Silymarin versus Silymarin and Green Coffee Extract on Thioacetamide Induced Liver Injury in Adult Male Albino Rats (Histological and Immunohistochemical Study)
}

\section{Original \\ Article}

\author{
Sara M. Abdel Aal, Hanaa S. E. Mousa, Samah M. Ahmed \\ Department of Histology and Cell Biology, Faculty of Medicine, Zagazig University, Zagazig, \\ Egypt
}

\begin{abstract}
Background: Thioacetamide (TAA) is a potent hepatotoxic agent used to induce liver toxicity in experimental animal models. Protective role of silymarin in liver intoxication was proved. Coffee is the most popular beverage used in the world. Consumption of green coffee bean extract has many benefits on health in general, and liver in particular.

Aim of work: To evaluate the potential role of adding green coffee extract to silymarin in improving thioacetamide induced hepatic injury in rats.

Materials and methods: Thirty six albino rats were divided into 4 groups; group I (control group), group II (thioacetamide group), group III (Silymarin group) and Group IV (Silymarin and green coffee extract group). Biochemical analysis for liver function, antioxidant enzyme assay were performed. Liver sections were stained using hematoxylin and eosin, Masson trichrome stains and immunohistochemical expression for caspase-3. Morphometric and statistical analysis were done.

Results: Liver functions of group II showed significant deterioration which slightly improved in group III and tend to be normal in group IV. Antioxidant enzyme levels of groupII and group III were significantly lower than that of group I; group III and group IV levels were significantly higher than that of group II. Liver sections of group II showed massive dilated congested portal vein, bile duct proliferation, and mononuclear cellular infiltrates. Group III showed slightly dilated congested portal vein in some areas while appeared normal in other areas. In group IV portal area appeared almostly normal. Marked increased collagen deposition was detected in group II, decreased in group III and markedly decreased in group IV. Immunohistochemical expression of caspase-3 was increased in group II, lower in group III and significantly low in group IV. In conclusion: Adding green coffee extract to silymarin potentiate the therapeutic effect of silymarin in improving experimentally induced hepatic injury by thioacetamide in rats.
\end{abstract}

Received: 10 September 2018, Accepted: 30 October 2018

Key Words: Green coffee extract, liver, silymarin, thioacetamide.

Corresponding Author: Sara M. Abdel Aal, MD, Department of Histology, Faculty of Medicine, Zagazig University, Tel.: +20 1001830969, E-mail: sara_mma@yahoo.com

ISSN: $1110-0559$, Vol. 42, No. 1

\section{INTRODUCTION}

Liver is a vital organ that plays a vital role in human physiology like metabolism of macromolecules and synthesis of useful components. Exposure to chemicals such as thioacetamide (TAA), alcohol, D-galactosamine, environmental pollutants and the abuse of drugs asparacetamol or rifampicin can damage hepatocytes leading to hepatotoxicity and liver fibrosis ${ }^{[1 \& 2]}$. Liver fibrosis is a major health problem resulting in a significant morbidity and mortality. Up-to-date, there is no standard treatment for fibrosis because of its complex pathogenesis ${ }^{[3]}$. Acute liver injury, fibrosis or cirrhosis can be experimentally induced by various chemicals, such as CCl4, thioacetamide (TAA), and ethionine ${ }^{[4 \& 5]}$.

TAA is a potent hepatotoxic agent and is widely used to induce liver toxicity in experimental animal models. It causes acute liver toxicity by interfering with the transfer of
RNA to cytoplasm from the nucleus, which leads to injury to the membrane. Basically, microsomal CYP2E1 converts TAA through two steps to "TAA-s-oxide or sulfoxide" and then to a bioactive metabolite TAA-S, S-dioxide which acts as a direct hepatotoxicant and causes centrilobular necrosis ${ }^{[6]}$.

The rate of morbidity and mortality due to hepatotoxicity or liver dysfunction is raising, which makes it a major health problem throughout the world posing a big challenge to health-care professionals, drug regulatory agencies, and pharmaceutical industry to find an adequate, suitable treatment ${ }^{[7]}$.

Thus, experimental models of toxic liver injury induced by TAA may be useful to evaluate the pharmacological effects of candidate hepatoprotectants, including Silymarin,coffee and caffeine products. The use of natural products in the prevention and treatment of liver diseases 
has gained considerable popularity ${ }^{[8]}$.

Silymarin extract contains approximately $65 \%$ to $80 \%$ flavonolignans (silybin A, silybin B, isosilybin A, isosilybin B, silychristin and silydianin), a small proportion of flavonoids, fatty acids and polyphenolic compounds, which possess a range of metabolic regulatory effects ${ }^{[9]}$. The hepatoprotective properties of Silymarin in liver intoxication have been previously described ${ }^{[10]}$.

Coffee is the most popular beverage used worldwide. Consumption of coffee has many benefits on health in general, and liver health in particular.It is an important source of bioactive phytochemicals including; methylxanthines (e.g. caffeine), amino acids, antioxidants like chlorogenic acid(CGA), tocopherols and polyphenols ${ }^{[11,12 \& 13]}$.

To avoid loss of the beneficial compounds of coffee, it can be used as green coffee bean extract (CGBE). It is made up of unroasted coffee beans and contains higher amounts of bioactive phytochemicals than that for the usual roasted coffee that is currently used. It has biological effects mostly related to their antioxidant and anti-inflammatory

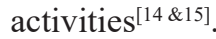

A lot of interest has been generated in the overall beneficial effects of coffee consumption that plays a protective role against various diseases of modern society ${ }^{[16 \& 17]}$. Moreover, a number of studies have suggested the effect of coffee constituents on liver function, development and progression of liver diseases ${ }^{[18]}$. Therefore, the aim of this study was to evaluate the potential role of adding green coffee extract to silymarin in improving thioacetamide induced hepatic injury in rats.

\section{MATERIAL S AND METHODS}

\section{Chemicals:}

Thioacetamide was purchased from Sigma Chemical Company (St. Louis, MO,USA).

Pure sample of silymarin was obtained from Sigma Chemicals, USA. Silymarin was dissolved in distilled water, then administered orally to the animals by gastric intubation using a force feeding needle.

GCBE was purchased in the form of Svetol, from Holland \& Barrett, Cardiff; UK.

\footnotetext{
Animals:

Thirty six adult Wistarmale albino rats (2-3 months) weighing 200-230 gm. were purchased from the Animal House Colony of the National Research Center, Dokki, Cairo, Egypt. They were kept under controlled conditions, standard humidity, and a temperature of $22 \pm 2^{\circ} \mathrm{C}$ in plastic cages. The study was carried out inFaculty of Medicine, Zagazig University according to the guidelines for animal research issued by the National Institute of Health, and approved by Animal Ethics Committee, Zagazig University, Zagazig, Egypt.
}

\section{Experimental design:}

Rats were randomly divided into 4 groups (9 rats/ group);

Group I served as the control group where rats received normal saline by intraperitoneal injection twice/week for 6 weeks $^{[19]}$.

Group II (thioacetamide treated group); rats were injected thioacetamide $(100 \mathrm{mg} / \mathrm{kg}$ body weight intraperitoneally) twice/week for 6 weeks ${ }^{[19]}$.

Group III rats were injected thioacetamide in the same way as group II,then they were received Silymarin $(100 \mathrm{mg}$ $/ \mathrm{kg} /$ day) orally by gastric gavage for 6 weeks $^{[19]}$.

Group IV rats were injected thioacetamide in the same way as group II, then they were received Silymarin(100/ $\mathrm{mg} / \mathrm{kg} /$ day) by gastric gavage together with GCBE (200 $\mathrm{mg} / \mathrm{kg} /$ day) orally for 6 weeks ${ }^{[20 \& 21]}$.

At the end of experiment, liver tissue was dissected. Each harvested liver was divided into two halves; one for homogenate and the other for histological and immunohistochemical study.

\section{Biochemical study:}

\section{Biochemical analysis for assessment of liver function}

Blood samples were collected just before sacrifice from the tail veins for assessment of liver function. Serum alanine transaminase (ALT), and aspartate transaminase (AST) activities were determined using kits provided by Elitech (France). They were measured by spectrophotometer ${ }^{[2]}$.

\section{Antioxidant enzymes assays ${ }^{[23]}$ :}

One half of the livers were used for estimation of Superoxide Dismutase (SOD) and Glutathione levels (GSH) was performed in the Department of Biochemistry, Faculty of Medicine, Zagazig University.

\section{Total Superoxide Dismutase (SOD) activity:}

SOD activity (antioxidant biomarker) was measured in the liver homogenate using a commercial chemical colorimetrical assay kit (Biodiagnostic, Cairo, Egypt).

\section{Glutathione levels (GSH):}

Reduced GSH was determined in the liver homogenates using a commercial chemical kit (Biodiagnostic, Cairo, Egypt).

\section{Histological methods:}

\section{(a) Histological study}

Liver tissue was excised and fixed in $10 \%$ buffered formalin saline. Then, they were processed to obtain $5 \mu \mathrm{m}$-thick paraffin sections. Sections were then stained with hematoxylin and eosin (H\&E) stain ${ }^{[24]}$ and Masson trichrome stain ${ }^{[25]}$ 


\section{(b) Immunohistochemical study}

Immunohistochemical expression of caspase-3 was performed using streptavidin-biotin complex immuneperoxidase system. Serial sections of paraffin-embedded specimens were deparaffinized on charged slides. sections were then processed according to the method described in $^{[26]}$.

\section{Morphometric Analysis:}

The diameter of central vein was measured from photos of X 400 magnification using digimizer 4.3.2. image analysis software (MedCalc Software bvba, Belgium).The area percentage of collagen fibers and area percentage of immune reaction to caspase 3 were measured using the Fiji Image J (1.51n, NIH, USA) program ${ }^{[27]}$.

\section{Statistical analysis:}

Statistical analysis was performed using the IBM SPSS 18.0 software. One-way analysis of variance (ANOVA) was used, followed by Posthoc least significant difference (LSD) test to evaluate the differences between the groups. For all comparison $P<0.05$ were considered as significant difference ${ }^{[28]}$.

\section{RESULTS}

\section{Biochemical results}

\section{Effect of GCBE on liver function tests:}

There was a significant difference between groups using one-way ANOVA test $(\mathrm{P}=0.001 *)$. Using LSD test, ALT levels of thioacetamide group and Silymarin treated group were significantly higher than that of control group. ALT level of Silymarin treated group and Silymarin \&GCBE treated group were significantly lower than that of thioacetamide group. There was a significant difference in ALT levels from Group IV(Silymarin and GCBE treated group) and Group III (Silymarin treated group) (Table $1 \&$ Bar chart 1).

There was a highly significant difference between groups using one-way ANOVA test $\left(P<0.001^{*}\right)$. Using LSD test, AST levels of thioacetamide group and Silymarin treated group were significantly higher than that of control group. AST level of Silymarin treated group and Silymarin\& GCBE treated group were significantly lower than that of thioacetamide group. There was a significant difference in AST levels from Silymarin\& GCBE treated group and Silymarin treated group (Table 1\& Bar chart 2).

\section{Effect of GCBE on GSH level and SOD activity:}

There was a significant difference between groups using one-way ANOVA test $(P<0.001 *)$. Using LSD test, GSH and SOD levels of thioacetamide group and Silymarin treated group were significantly lower than that of control group.GSH and SOD levels of Silymarin treated group and Silymarin\& GCBE treated group were significantly higher than that of thioacetamide group. There was a significant difference in GSH and SOD levels between Silymarin\&
GCBE treated group and Silymarin treated group (Table 2 \& Bar charts 3, 4).

\section{Histological results}

Control group sections stained with $\mathrm{H}$ \& E showed normal polygonal classic hepatic lobules with tightly packed cords of hepatocytes radiating from the central vein. Portal area was seen at the periphery of the lobule (Fig. 1A). Hepatocytes of the same group contained vesicular nuclei and acidophilic cytoplasm, some of them were binucleated. Blood sinusoid inbetween hepatocyte cords and their lining endothelium were seen (Fig. 1B). TTA treated group liver sections showed massive dilated congested portal vein, with area of homogenous oesinophilic material, bile duct proliferation, hepatocytes had deep acidophilic cytoplasm with small dark nuclei and mononuclear cellular infiltrates were seen (Fig. 1C). Dilated congested central vein was detected (Fig. 1D). Liver sections of Silymarin treated group revealed many hepatocytes with vesicular nuclei and acidophilic cytoplasm (Fig. 1E, F\& G). Portal area showed mononuclear cellular infiltrates, slightly dilated congested portal vein in some areas as in (Fig. 1E) while appeared normal in other areas with normal appearance of branches of hepatic artery and bile duct were seen as in (Fig. 1F), dilated congested central vein was still detected in some areas of this group (Fig. 1G). In Silymarin and GCBE treated group portal area appeared almostly normal with normal appearance of branches of portal vein, hepatic artery and bile duct apart from minimal cellular infiltration were seen, hepatocytes appeared with vesicular nuclei and acidophilic cytoplasm (Fig. 1H). Minimal congestion in central vein was observed in this group (Fig. 1I).

Masson trichrome stained sections of the control group revealed few collagen fibers around central vein and portal area (Fig. 2A\&B). Marked increased collagen deposition around central vein and in between hepatocytes(Fig. 2C) and in portal area(Fig. 2D) were detected in TTA treated group. Few collagen fibers were found in Silymarin treated group around central vein (Fig. 2E) and in portal area (Fig. 2F). Minimal amount of collagen deposition was seen in Silymarin\& GCBE treated group around central vein (Fig. 2G) and in portal area (Fig. 2H).

\section{Immunohistochemical results:}

Examination of Caspase 3 immunostained liver sections of control group revealed negative caspase-3 immunoexpression in cytoplasm of hepatocytes (Fig. 3A). liver sections of TTA treated group showed strong positive immunoreaction for caspase -3 in cytoplasm of most of hepatocytes (Fig. 3B), however Silymarin treated group revealed mild positive caspase- 3 immunoexpression in some hepatocytes (Fig. 3C).Silymarin and GCBE treated group showed few areas of weak positive caspase-3 immunoexpression in cytoplasm of hepatocytes (Fig. 3D).

\section{Morphometric and statistical results:}

\section{Long and short diameters of central vein ( $\mu \mathrm{m})$}


There was a highly significant difference between groups using one-way ANOVA test $(P<0.001 *)$. Using LSD test, long diameter of central veinof thioacetamide group and Silymarin treated group were significantly higher than that of control group.long diameters of central vein of Silymarin treated group and Silymarin\& GCBE treatedgroup were significantly lower than that of thioacetamide group. There was a significant difference in long diameters of central vein from Silymarin and GCBE treated group and Silymarin treated group (Table 3\&Bar chart 5A).

There was a highly significant difference between groups using one-way ANOVA test $(P<0.001 *)$. Using LSD test, short diameters of central vein of thioacetamide group and Silymarin treated group were significantly higher than that of control group.Short diameters of central vein of Silymarin treated group and Silymarin\& GCBE treatedgroup were significantly lower than that of thioacetamide group. There was a significant difference in short diameters of central vein from Silymarin and GCBE treated group and Silymarin treated group(Table $3 \& B a r$ chart 5B)

\section{The area percentage of collagen fibers:}

There was a highly significant difference between groups using one-way ANOVA test $\left(P<0.001^{*}\right)$. Using LSD test ,the area percentage of collagen fibers of thioacetamide group and Silymarin treated group were significantly higher than that of control group.The area percentage of collagen fibers of Silymarin treated group and Silymarin and GCBE treated group were significantly lower than that of thioacetamide group. There was a significant difference in the area percentage of collagen fibers from Silymarin\& GCBE treated group and Silymarin treated group (Table $4 \&$ Bar chart 6)

\section{The area percentage of immunoreaction to caspase 3}

There was a highly significant difference between groups using one-way ANOVA test $(P<0.001 *)$. Using LSD test, the area percentage of immunoreaction to caspase 3 of thioacetamide group and Silymarin treated group were significantly higher than that of control group.The area percentage of immune reaction to caspase 3 of Silymarin treated group and Silymarin\& GCBE treated group were significantly lower than that of thioacetamide group. There was a significant difference in the area percentage of immunoreaction to caspase 3 from Silymarin\& GCBE treated group and Silymarin treated group (Table 5\& Bar chart 7).

Table 1: The effect of Silymarin alone and combination of Silymarin and GCBE on the liver function tests.

\begin{tabular}{|c|c|c|c|c|c|}
\hline Groups & Control Group & Thioacetamide Group & Silymarin treated & Silymarin \&GCBE treated & $P$ value \\
\hline $\operatorname{ALT}(\mathrm{U} / \mathrm{L})$ & $64.9 \pm 6.01$ & $92.4^{\mathrm{a}} \pm 25.6$ & $80.82^{\mathrm{ab}} \pm 15.8$ & $68.13^{\mathrm{bc}} \pm 4.5$ & $0.001 *$ \\
\hline AST (U/L) & $279.3 \pm 28.9$ & $470.4^{a} \pm 94.1$ & $376.1^{\mathrm{ab}} \pm 99.6$ & $297.9^{\mathrm{bc}} \pm 52.5$ & $<0.001 *$ \\
\hline
\end{tabular}

- Data represent mean $\pm \mathrm{SD}<0.05$ was considered significant $\mathrm{n}=9$.

a: Significant difference from the control group.

b: Significant difference from the thioacetamide untreated group.

c: Significant difference from the Silymarin treated group.

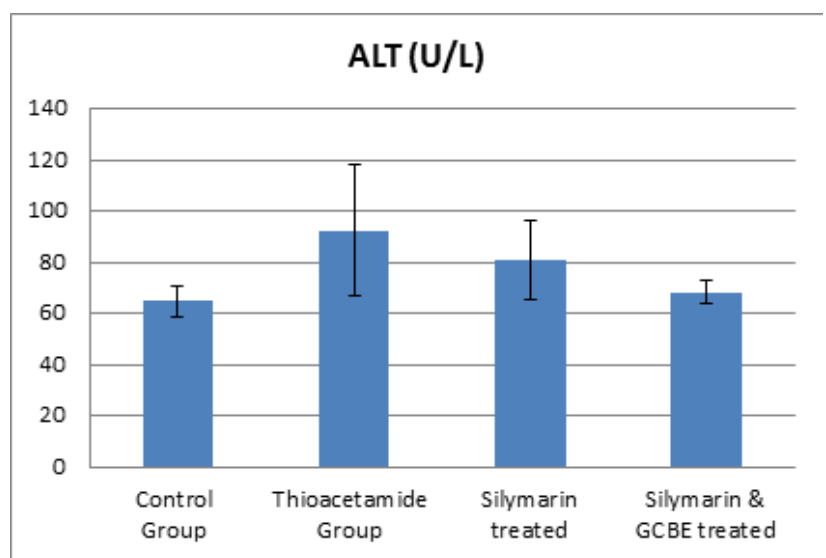

Bar chart 1: Comparison between mean values of ALT level among the studied groups $(\mathrm{N}=9, \mathrm{P}=0.001 *)$.

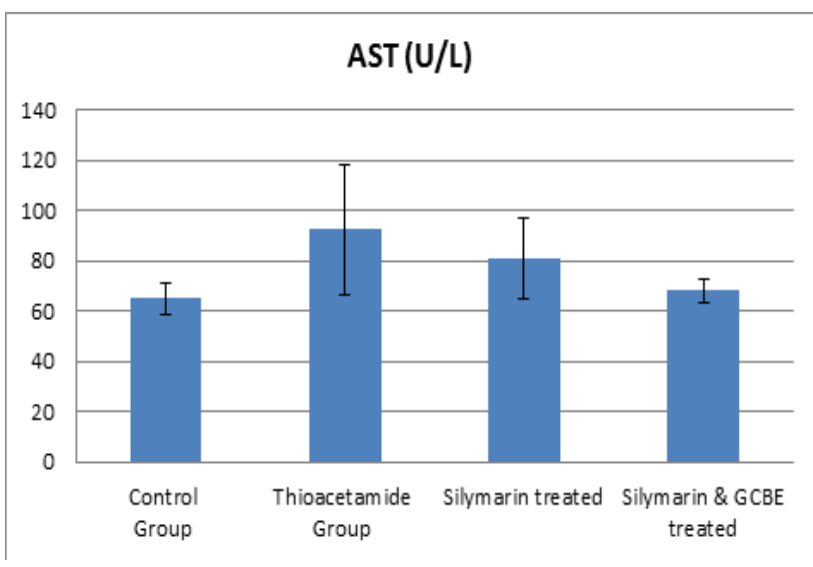

Bar chart 2: Comparison between mean values of AST level among the studied groups $\left(\mathrm{N}=9, P<0.001^{*}\right)$. 
Table 2: The effect of Silymarin alone and combination of Silymarin and GCBE on levels of GSH and SOD activity in the liver homogenates of rats.

\begin{tabular}{|c|c|c|c|c|c|}
\hline & Control Group & Thioacetamide Group & Silymarin treated group & Silymarin \&GCBE treated group & Pvalue \\
\hline $\mathrm{GSH}(\mu \mathrm{mol} / \mathrm{g})$ & $1.60 \pm 0.3$ & $0.66^{\mathrm{a}} \pm 0.2$ & $0.89^{\mathrm{ab}} \pm 0.2$ & $1.53^{\mathrm{bc}} \pm 0.2$ & $0.001 *$ \\
\hline SOD (U/mg protein) & $40 \pm 6.1$ & $28.3^{\mathrm{a}} \pm 5.3$ & $33.6^{\mathrm{ab}} \pm 4.4$ & $38.8^{\mathrm{bc}} \pm 4.9$ & $<0.001 *$ \\
\hline
\end{tabular}

- Data represent mean $\pm \mathrm{SD}<0.05$ was considered significant $\mathrm{n}=9$.

a: Significant difference from the control group.

b: Significant difference from the thioacetamide untreated group.

c: Significant difference from the silymarin treated group.

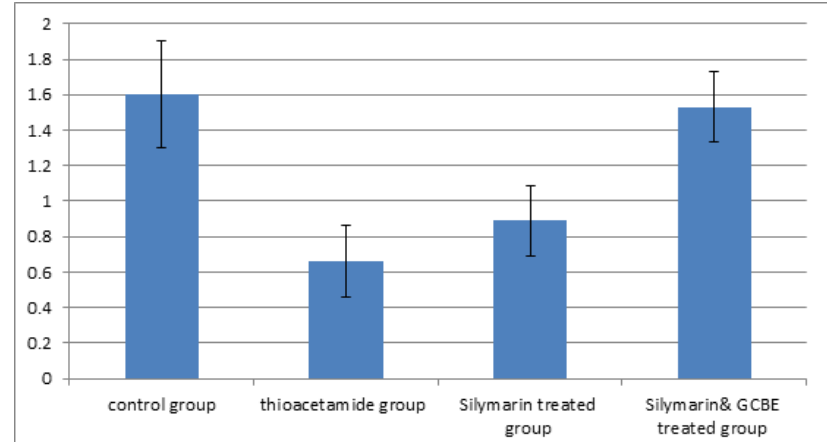

Bar chart 3: Comparison between mean values of GSH ( $\mu \mathrm{mol} / \mathrm{g})$ among the studied groups $\left(\mathrm{N}=9, P<0.001^{*}\right)$.

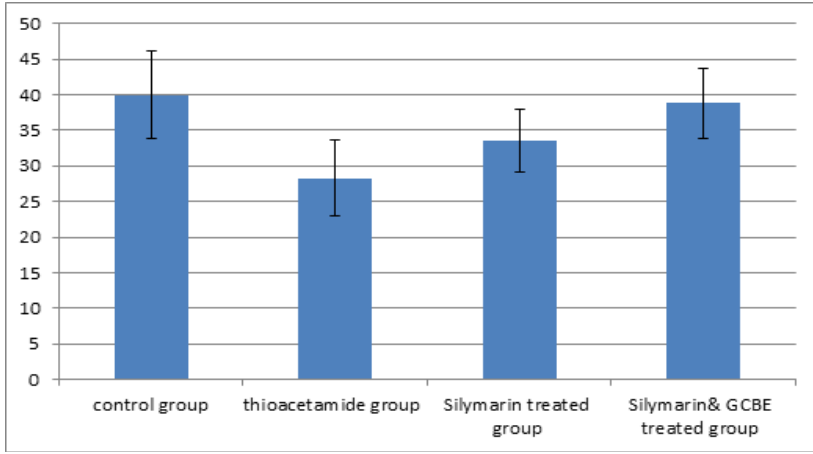

Bar chart 4: Comparison between mean values of SOD (U/mg protein) among the studied groups $\left(\mathrm{N}=9, P<0.001^{*}\right)$.

Table 3: The effect of Silymarin alone and combination of Silymarin and GCBE on the long and short diameters of central vein $(\mu \mathrm{m})$.

\begin{tabular}{|c|c|c|c|c|c|}
\hline & Control Group & Thioacetamide Group & Silymarin treated group & Silymarin \&GCBE treated group & Pvalue \\
\hline Long diameter of central vein & $65.75 \pm 6.6$ & $127.98 \pm 34.6 \mathrm{a}$ & $101.1 \pm 33.2 \mathrm{ab}$ & $69.4 \pm 5.5 b c$ & $0.001 *$ \\
\hline Short diameter of central vein & $45.9 \pm 4.99$ & $66.2 \pm 10.8 \mathrm{a}$ & $54.5 \pm 7.2 \mathrm{ab}$ & $46.4 \pm 4.8 \mathrm{bc}$ & $<0.001^{*}$ \\
\hline
\end{tabular}

- Data represent $\operatorname{mean} \pm \mathrm{SD}<0.05$ was considered significant $\mathrm{n}=9$.

a: Significant difference from the control group.

b: Significant difference from the thioacetamide untreated group.

c: Significant difference from the silymarin treated group.
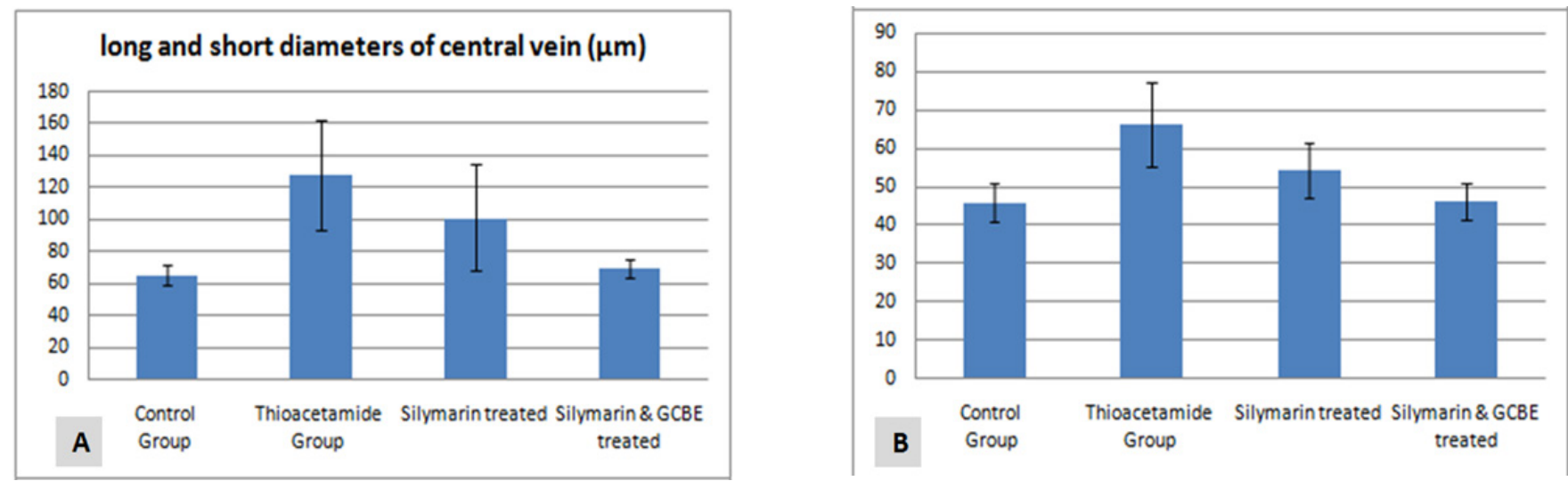

Bar chart 5: Comparison between mean values of long (A) and short (B) diameters of central vein $(\mu \mathrm{m})$ among the studied groups $(\mathrm{N}=9, P<0.001 *)$. 
Table 4: The effect of Silymarin alone and combination of Silymarin and GCBE on the area percentage of collagen fibers

\begin{tabular}{|c|c|c|c|c|c|}
\hline & Control Group & Thioacetamide Group & Silymarin treated group & Silymarin \&GCBE treated group & Pvalue \\
\hline area percentage of collagen fibers & $1.1 \pm 0.3$ & $11.04 \pm 2.9 \mathrm{a}$ & $6.4 \pm 1.2 \mathrm{ab}$ & $1.19 \pm 0.3 b c$ & $<0.001^{*}$ \\
\hline
\end{tabular}

- Data represent mean $\pm \mathrm{SD}<0.05$ was considered significant $\mathrm{n}=9$.

a: Significant difference from the control group.

b: Significant difference from the thioacetamide untreated group.

c: Significant difference from the Silymarin treated group.

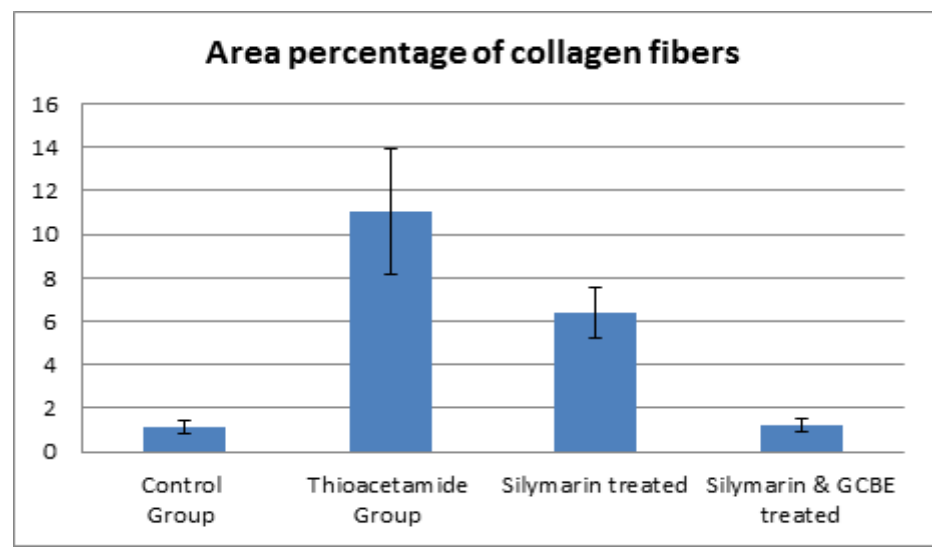

Bar chart 6: Comparison between mean values of area percentage of collagen fibers among the studied groups.

Table 5: The effect of Silymarin alone and combination of Silymarin and GCBE on the area percentage of caspase 3immune reaction:

\begin{tabular}{ccccc}
\hline & Control Group & Thioacetamide Group & Silymarin treated group & Silymarin \&GCBE treated group \\
Area percentage of caspase & $0.73 \pm 0.14$ & $10.4 \pm 1.4 \mathrm{a}$ & $5.1 \pm 1.3 \mathrm{ab}$ & $<0.001 *$ \\
3 immune reaction & & & $1.15 \pm 0.42 \mathrm{bc}$ \\
\hline
\end{tabular}

- Data represent mean $\pm \mathrm{SD}<0.05$ was considered significant $\mathrm{n}=9$.

a: Significant difference from the control group.

b: Significant difference from the thioacetamide untreated group.

c: Significant difference from the Silymarin treated group.

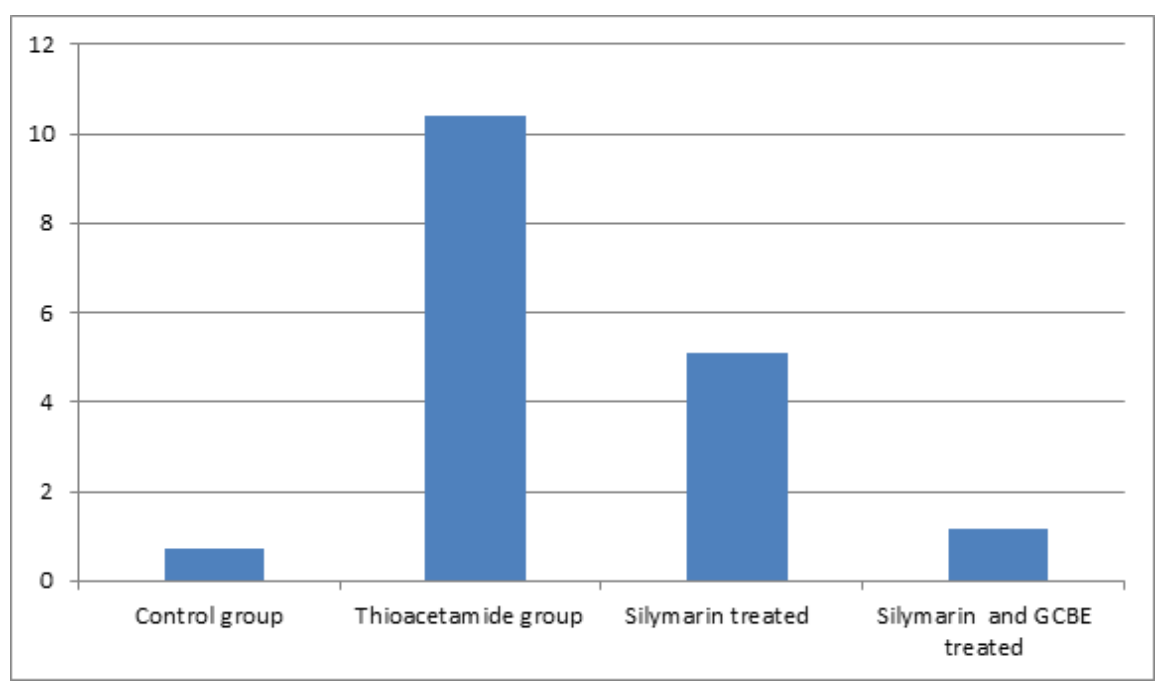

Bar chart 7: Comparison between mean values of area percentage of caspase 3 immune reaction among the studied groups. 


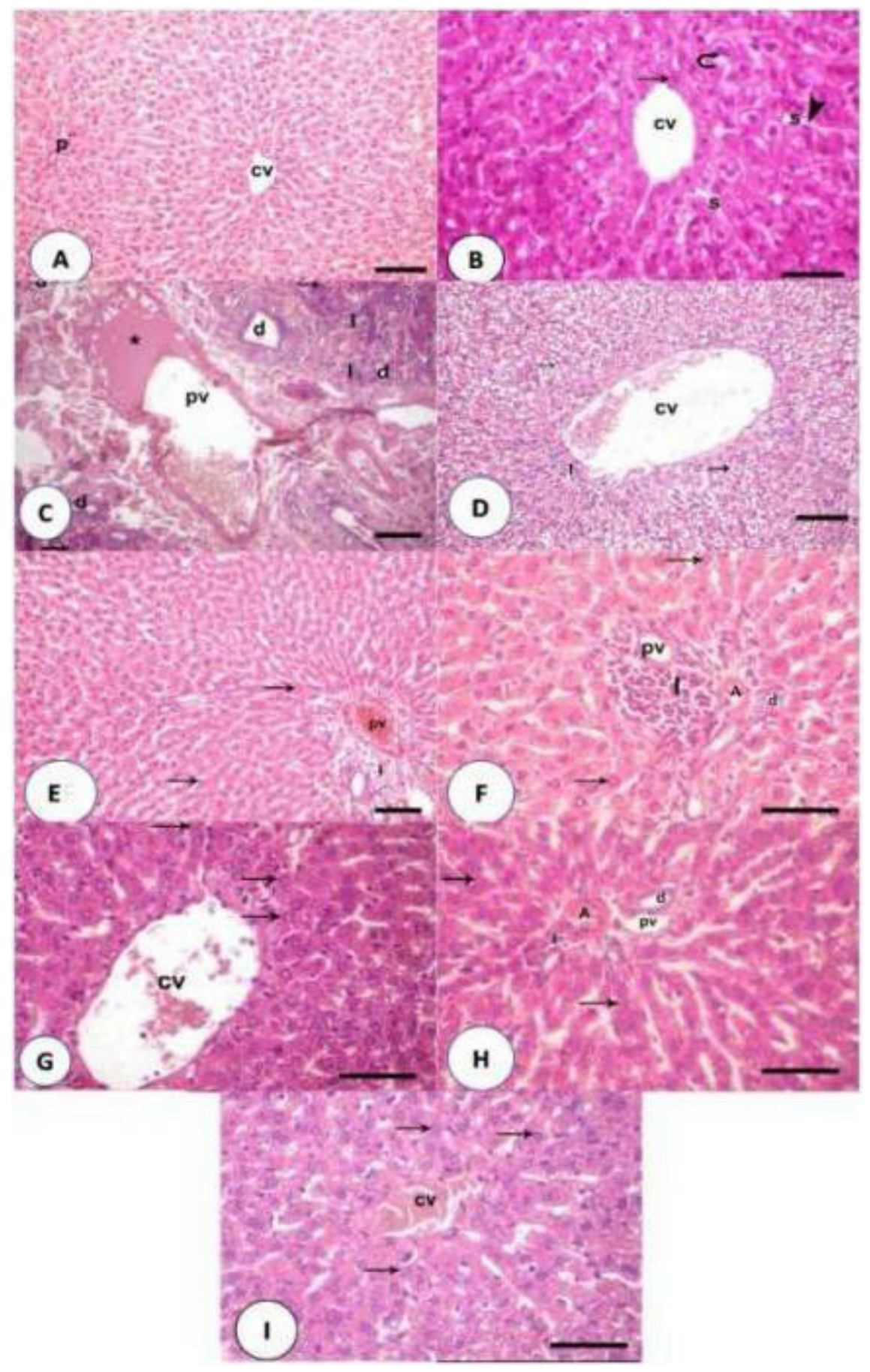

Fig.1: Haematoxylin and Eosin stained liver sections A: control group shows normal polygonal classic hepatic lobules with tightly packed cords of hepatocytes are radiating from the central vein $(\mathrm{cv})$, portal area $(\mathrm{P})$ is seen at the periphery of the lobule. B: the higher magnification shows hepatocytes with vesicular nuclei and acidophilic cytoplasm (arrow), some hepatocytes are binucleated (curved arrow). Blood sinusoids (S) inbetweenhepatocytic cords and their lining endothelium (arrows head) are seen. TTA treated group shows C: massive dilated congested portal vein (pv), with area of homogenous oesinophilic material (asterisk), bile duct proliferation (d), hepatocytes have deep acidophilic cytoplasm with small dark nuclei (arrow) and mononuclear cellular infiltrates (I) are seen. D: Dilated congested central vein (cv) is seen. Hepatocytes have vacuolated cytoplasm with small dark nuclei (arrows) and pericentral cellular infiltrates (I) are seen. In Silymarin treated group E \& F many hepatocytes appear with vesicular nuclei and acidophilic cytoplasm (arrows), portal area shows mononuclear cellular infiltrates (I), slightly dilated congested portal vein (pv) in some areas as in (E) while appeared normal in other areas as in (F), normal appearance of branches of hepatic artery (A) and bile duct (d) are seen in (F). G: dilated congested central vein (cv) is still detected in some areas, hepatocytes appear with vesicular nuclei and acidophilic cytoplasm (arrows). In Silymarin\& Green coffee treated group H: portal area appear almostly normal with normal appearance of branches of portal vein (pv), hepatic artery (A) and bile duct (d) apart from minimal cellular infiltration(I) are seen, hepatocytes appear with vesicular nuclei and acidophilic cytoplasm (arrows). I: minimal congestion in central vein (cv) is observed \& most of hepatocytes appear with vesicular nuclei and acidophilic cytoplasm (arrows). (H\&E: A x 200; scale bar $30 \mu \mathrm{m}, \mathrm{B}$ x400; scale bar $50 \mu \mathrm{m}, \mathrm{C}$, x 200; scale bar $50 \mu \mathrm{m}, \mathrm{D}, \mathrm{E}$ x 200; scale bar $40 \mu \mathrm{m}, \mathrm{F}, \mathrm{G}, \mathrm{H}, \mathrm{I}$ x 40 ; scale bar $40 \mu \mathrm{m})$ 


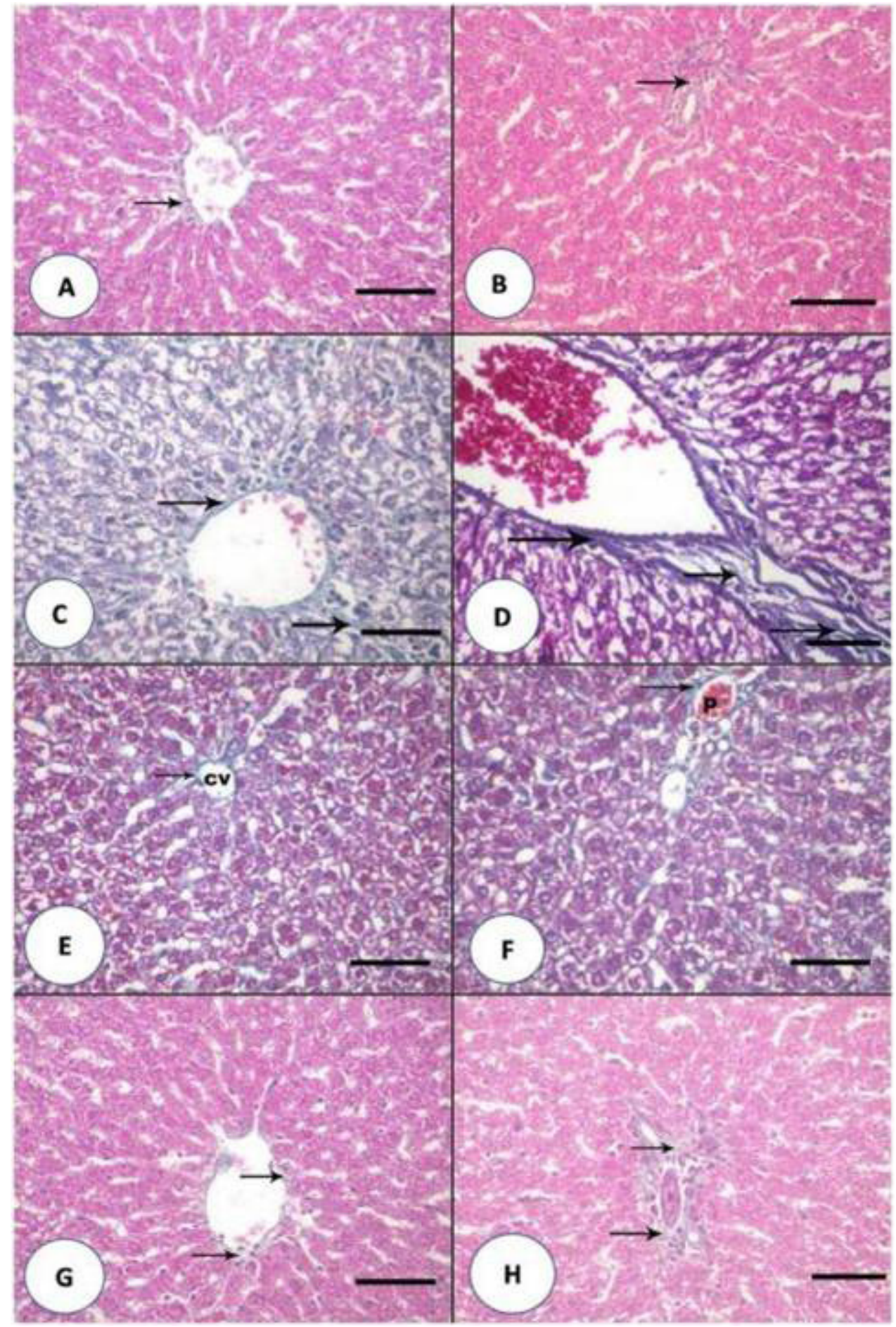

Fig.2: Masson trichrome stained sections showing A\&B: few collagen fibers around central vein (A) and portal area (B) in control group (arrows), C\&D: marked increase in collagen deposition around central vein and in between hepatocytes (C) and in portal area (D) in TTA treated group, In E\&F Few collagen fibers can be seen in Silymarin treated group around central vein (E) and portal area (F). In G\&H show minimal amount of collagen deposition around central vein $(G)$ and in portal area $(H)$ in Silymarin \& Green coffee treated group. (Masson trichrome x400; scale bar $40 \mu \mathrm{m}$ ) 


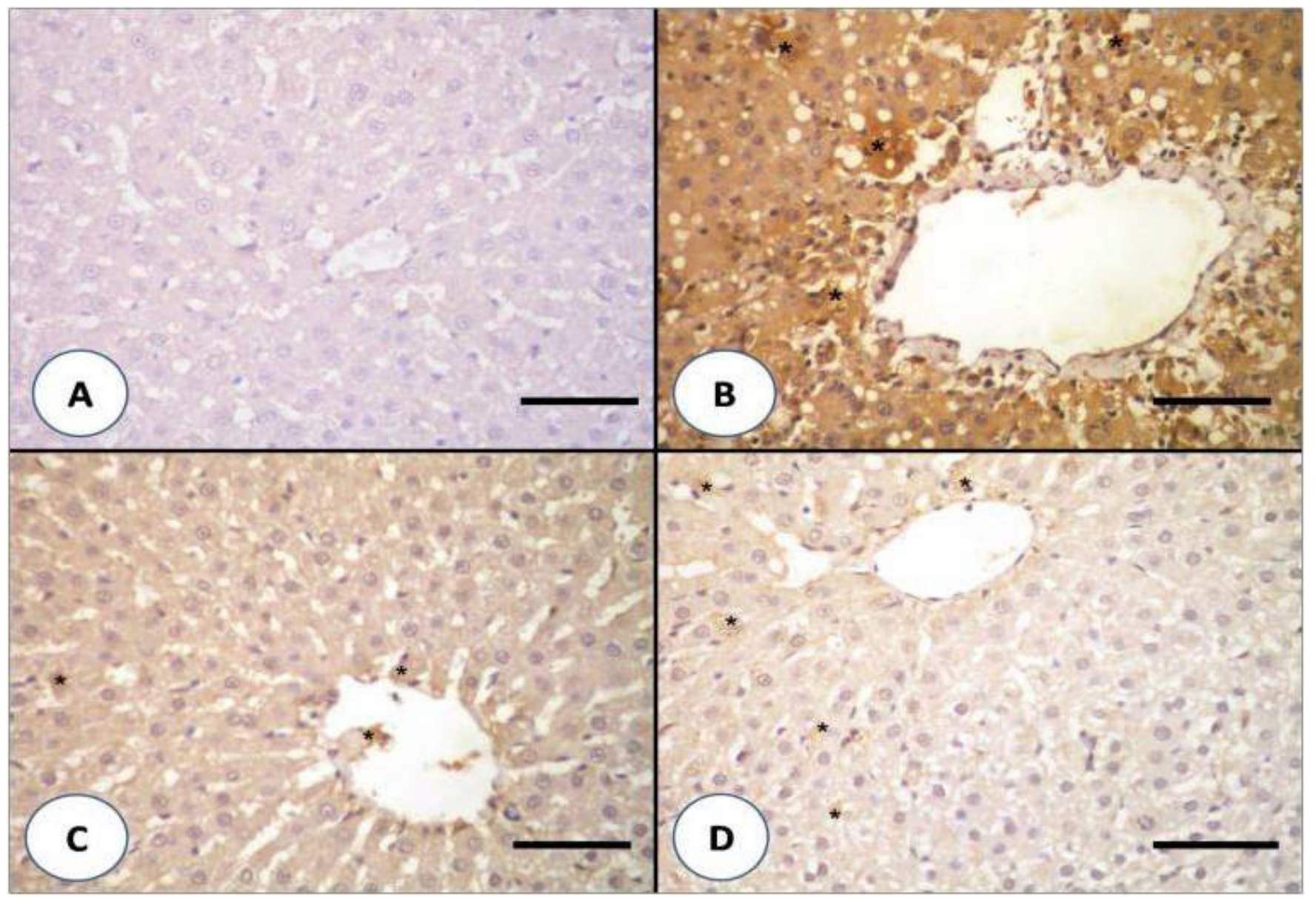

Fig.3: Caspase 3 immunostained liver sections showing: control group (A): negative caspase-3 immunoexpression in cytoplasm of hepatocytes TTA treated group (B): Strong positive immunoreaction for caspase -3 (asterisks) in cytoplasm of most of hepatocytes. Silymarin treated group (c): Mild positive caspase-3 (asterisks) immunoexpression in some hepatocytes. Silymarin\& Green coffee treated group (D): Few areas of weak positive caspase-3 immunoexpression (asterisks) in cytoplasm of hepatocytes.

\section{DISCUSSION}

Liver fibrosis is a major health problem ${ }^{[29]}$. The present study evaluated the potential role ofsilymarin and green coffee extract to guard against thioacetamide induced hepatic injury and fibrosis in rats.

In the current study, ALT andAST levels of thioacetamide group and silymarin treated group were significantly higher than that of the control group.ALT and AST levels of silymarin treated group and Silymarin\&GCBE treated group were significantly lower than that of thioacetamide group. There was a significant difference in ALT and AST levels between silymarin treated group and silymarin\& GCBE treated group.

A significant increase in the level of serum transaminases is considered as a biomarker of cellular leakage and damage of the cell membrane of liver. ALT is a sensitive and important biomarker of liver toxicity. The serum level of ALT activity directly linked to the damage to the hepatocytes. The serum level of AST is another important biomarker of liver functions. TAA intoxicated rats showed significant alterations in the level of serum biomarker enzymes of liver, kidneys, and lipid profile ${ }^{[30]}$.
A single dose of TAA causes necrosis along with increased level of serum transaminases and bilirubin concentrations in rats $^{[31 \& 32]}$.

Several antioxidant agents, including Silymarin, vitamins ( $\mathrm{C}$ and $\mathrm{E}$ ), and melatonin have been reported to reduce induced hepatic toxicity ${ }^{[33]}$. Silymarin is a flavonoid extracted from the milk thistle Silybummarianum. Although Silymarin has been described to possess antioxidant, immunomodulatory, antiproliferative, antifibrotic, and antiviral activities ${ }^{[34]}$, its mechanisms of action still have not been well established ${ }^{[35]}$.

Wadhawan et al. ${ }^{[12]}$ reported that consumption of coffee has been shown to benefit health in general, and liver health in particular. The clinical evidence of benefit of coffee consumption in Hepatitis B and C, as well as nonalcoholic fatty liver disease and alcoholic liver disease, has also been presented. Coffee consumption is associated with improvement in liver enzymes (ALT, and AST), especially in individuals with risk for liver disease. Coffee intake more than 2 cups per day in patients with preexisting liver disease has been shown to be associated with lower incidence of fibrosis and cirrhosis, lower hepatocellular carcinoma rates, as well as decreased mortality. 
In the present work, GSH and SOD levels of thioacetamide group and silymarin treated group were significantly lower than that of the control group.GSH and SOD levels of silymarin treated group and silymarin \& GCBE treated group were significantly higher than that of thioacetamide group. There was a significant difference in GSH and SOD levels between silymarin \& GCBE treated group and silymarin treated group.

TAA is a potent hepatic toxicant, and carcinogenic agent in rats. TAA administration at a dose of $100 \mathrm{mg} / \mathrm{kg}$ is reported to cause hepatorenal toxicity. The increased oxidative stress is considered as the main cause of TAAinduced hepatotoxicity. Also, chronic exposure of TAA may cause liver cirrhosis in rats. The mechanism of hepatorenal toxicity of TAA is due to interference of the RNA movement to cytoplasm from the nucleus, which results in injury to the membrane ${ }^{[6 \& 36]}$.

Silymarin protects against liver injury caused by ethanol administration. The effect may be related to alleviating lipid peroxidation and inhibiting the expression of NFkB. It can prevent lipid peroxidation, inhibit low-density lipoprotein oxidation and scavenge reactive oxygen species $\operatorname{ROS}^{[35 \& 37]}$. Moreover, it has anti-inflammatory effects which may relate its ability to inhibit NFkB, which contributes to the production of proinflammatory mediators such as IL-1 and IL -6, TNF- $\alpha$, and interferon (IFN)-- ${ }^{[38]}$.

Green coffee extract is a source of dietary antioxidants that may improve the quality of life.It is richin phenolic compounds (e.g. chlorogenic acid, caffeic acid andcaffeoyl tryptophan), cafestol, kahweol, nicotinic acid andcaffeine, the antioxidant and antimutagenic effects of which have been demonstrated in vitro.Antioxidants prevent free radical tissue damage byreducing or eliminating reactive oxygen species ${ }^{[39]}$.

In the current study, histological examination of $\mathrm{H} \& \mathrm{E}$ stained liver sections of TTA treated group showed massive dilated congested portal vein, with area of homogenous oesinophilic material and dilated congested central vein. Bile duct proliferation, hepatocytes had deep acidophilic cytoplasm with small dark nuclei and mononuclear cellular infiltrates were seen.

Experimental studies have shown that repeated TAA administrationinduces liver damage, and fibrosis that was associated with hepatocyte death and activation of Kupffercells (KC) and hepatic stellate cells. TAA is mainly responsible for hepatorenal toxicity. It causes an increase in the concentration of intracellular calcium, alteration in cell permeability, karyomegaly with increased nuclear volume, and mitochondrial inhibition which results in hepatic cell death $^{[40]}$.

Liver sections of Silymarin treated group revealed many hepatocytes with vesicular nuclei and acidophilic cytoplasm, the portal area showed mononuclear cellular infiltrates, slightly dilated congested portal vein in some areas while appeared normal in other areas with normal appearance of branches of hepatic artery and bile duct were seen.

The protective effect of Silymarin was attributed to its antioxidant and free radical scavenging properties ${ }^{[41]}$.

In Silymarin\& Green coffee treated group portal area appeared almostly normal with normal appearance of branches of portal vein, hepatic artery and bile duct apart from minimal cellular infiltration were seen, hepatocytes appeared with vesicular nuclei and acidophilic cytoplasm. Minimal congestion in central vein was observed in this group.

Caffeine present in green coffee provided an antifibrogenic, anti-inflammatory, and antioxidant effect thatwas associated with recovery of hepatic histological and functional alterations from TAA-induced hepatotoxicity ${ }^{[41]}$.

In the present work, marked increase in collagen fiber deposition around central vein, in-between hepatocytes and in the portal area was detected in Masson trichrome stained sections of TTA treated group. Few collagen fibers around central vein and in portal area in Silymarin treated group was detected. Minimal amount of collagen deposition was seen in Silymarin\& Green coffee treated group.

TAA induced liver toxicity with elevated liver enzymes and histological alterations, fatty changes, apoptosis, and fibrosis evidenced by increased immunohistochemical reaction to matrix metalloproteinase-9 (MMP-9) and collagen type IV in hepatocytes. Also, the levels of proinflammatory cytokines (TNF- $\alpha$, IL-1 $\beta$, and IL-6) in serum were significantly elevated. Co-treatment with caffeine and TAA restored normal liver structure and function ${ }^{[22]}$.

Receiving conventional and decaffeinated coffee and caffeine might be linked to the reduction in collagen deposition and fibrosis. Caffeine stronglydown-modulates expression of TGF-b-induced connective tissue growth factor (CTGF) in the hepatocytes by stimulating the degradation of SMAD 2 (a TGF-b effector), inhibition ofSMAD3 phosphorylation and up-regulation of peroxisome proliferator-activated receptor gamma $(\text { PPAR-c) })^{[33]}$

Examination of Caspase 3 immunostained liver sections of TTA treated group showed strong positive immunoreaction for caspase -3 in cytoplasm of most of hepatocytes, however Silymarin treated group revealedmild positive caspase-3 immunoexpression in some hepatocytes. Silymarin\& Green coffee treated group showed few areas of weak positive caspase-3 immunoexpression in cytoplasm of hepatocytes.

Several studies revealed that the administration Silymarin with $\mathrm{CCl} 4$ ameliorated the levels of Bax, $\mathrm{Bcl} 2$ and ALT which were disturbed after treatment rats with $\mathrm{CCl} 4^{[44 \& 45]}$. It can prevent lipid peroxidation, inhibit LDL oxidation and scavenge reactive oxygen species $(\mathrm{ROS})^{[37]}$. Moreover, it has anti-inflammatory effects which may relate its ability to inhibit the transcription factor NFkB, 
which contributes to the production of proinflammatory mediators such as interleukin (IL)- 1 and IL -6 , TNF- $\alpha$, lymphotoxin, granulocyte macrophage, colony-stimulating factor (GM-CSF) and interferon (IFN $\gamma)-\mathrm{c}^{[38]}$.

Some GCE constituents, suchas chlorogenic acid is the major active ingredient found in a variety offruits, dietary vegetables and many traditional Chinese medicines $^{[46,47 \text { and } 48]}$. CGA has been reported to possess antibacterial, antioxidant, and anti-carcinogenic properties. CGA has also been reported to be a potent polyphenolic antioxidant as it reduces the levels of the apoptosis related proteins, including caspase- 3 and $\mathrm{Bax}^{[49]}$.

\section{CONCLUSION AND RECOMMENDATIONS}

The results of this experimental study strengthened and provided additional insight to the important role of adding green coffee extract to silymarin in ameliorating TTA induced liver injury in albino rat model. Future studies should be carried out to delineate the mechanisms underlying their action.

\section{CONFLICTS OF INTEREST}

The authors declare there is no conflict of interest regarding the publication of this article.

\section{FUNDING STATEMENT}

The research was personally funded by all authors.

\section{ABBREVIATIONS}

TAA: Thioacetamide

CGA: Chlorogenic acid

Cc14:Carbonttetrachloride

SOD: Superoxide Dismutase

GCBE:Green coffee Bean extract

ALT: Alanine aminotransferase

AST: Aspartate aminotransferase

GGT: Gamma-glutamyltransferase

GGTP: Gamma-glutamyltranspeptidase

ALP: Alkaline phosphatase

MMP-9: Matrix metalloproteinase-9

ROS: Reactive oxygen species

\section{REFERENCES}

1. Moreira PR, Maioli MA, Medeiros HCD, Guelfi M, Pereira FTV, Mingatto FE. Protective effect of bixinon carbon tetrachloride induced hepatotoxicity in rats. Biol Res. 2014; 47-49.2.Ahmad A, AlAbbasiFA., SaidaS, Soad Sh A, Mohammed F. et al.Ameliorative Effect of Camel's Milk and Nigella Sativa Oil against Thioacetamide-induced Hepatorenal Damage in RatsPharmacogn Mag. 2018; 14(53): 27-35.
2. Rincón D, Lo Iacono O, Tejedor M, Hernando A, Ripoll C, Catalina MV, et al. Prognostic value of hepatic venous pressure gradient in patients with compensated chronic hepatitis C-related cirrhosis. Scand J Gastroenterol. 2013; 48: 487-495.

3. Natarajan SK, Thomas S, Ramamoorthy $P$, Basivireddy J, Pulimood AB, Ramachandran A et al.Oxidative stress in the development of liver cirrhosis: a comparison of two different experimental models. J GastroenterolHepatol 2006;21:947-57.

4. Manibusan MK, Odin M, Eastmind DA. Postulated carbon tetrachloride mode of action: a review. J Environ Sci Health C Environ CarcinogEcotoxicol Rev. 2007;25:185-209.

5. Chen TM, Subeq YM, Lee RP, Chiou TW, Hsu BG. Single dose intravenous thioacetamide administration as a model of acute liver damage in rats. Int J ExpPathol. 2008;89:223-31.

6. Ghabril M, Chalasani N, Björnsson E. Druginduced liver injury: A clinical update. CurrOpinGastroenterol. 2010;26:222-6.

7. Jaeschke H, McGill MR, Williams CD, and Ramachandran A. Current issues with acetaminophen hepatotoxicity-a clinically relevant model to test the efficacy of natural products. Life Sci, 2011; 88 (17-18): 737-45.

8. Comelli MC, Mengs U, Schneider C, and Prosdocimi M. Toward the definition of the mechanism of action of silymarin: activities related to cellular protection from toxic damage induced by chemotherapy. Integr Cancer Ther, 2007; 6(2): 120-9.

9. Nayak SS, Jain R, and Sahoo AK. Hepatoprotective activity of Glycosmispentaphylla against paracetamol-induced hepatotoxicity in Swiss albino mice. Pharm Biol, 2011; 49(2): 111-7.

10. Esquivel P, Jiménez VM. Functional properties of coffee and coffee by-products.Food Res Int. 2012;46(2):488-95.

11. Wadhawan M., Anil C. Anand, Coffee and Liver Disease ( J CLIN EXP HEPATOL, 2016;6:40-46.

12. Shahmohammadi, H. A., Hosseini, S. A., Hajiani, E., Malehi, A. S., \&Alipour, M. Effects of Green Coffee Bean Extract Supplementation on Patients with Non-Alcoholic Fatty Liver Disease: A Randomized Clinical Trial. Hepatitis Monthly, (2017).17(4);112-123.

13. Esquivel P, Jiménez VM. Functional properties of coffee and coffee by-products. Food Res Int. 2012; 46 (2): 488-95. 
14. Sarriá B, Martínez-López S, Mateos R, BravoClemente L. Long-term consumption of a green/ roasted coffee blend positively affects glucose metabolism and insulin resistance in humans. Food Res Int. 2016; 89:1023-8.

15. $\mathrm{Hu} \mathrm{G}$, Bidel $\mathrm{S}$, Jousilahti $\mathrm{P}$, Antikainen $\mathrm{R}$, Tuomilehto J. Coffee and tea consumption and the risk of Parkinson's disease. MovDisord.2007;22(15):2242-8

16. van Dam RM. Coffee consumption and risk of type 2 diabetes, cardiovascular diseases, and cancer. ApplPhysiolNutrMetab.2008;33(6):1269-83.

17. Johnson S, Koh WP, Wang R, Govindarajan S, Yu $\mathrm{MC}$, Yuan JM. Coffee consumption and reduced risk of hepatocellular carcinoma: findings from the Singapore Chinese Health Study. Cancer Causes Control. 2011;22(3):503-10.

18. Algandaby M. M., Antifibrotic effects of crocin on thioacetamide-induced liver fibrosis in mice Saudi Journal of Biological Sciences. (2018); 25, $747-754$

19. Choi B., Park S., Lee D., Lee H., Jin Y., Yang S., Suh J., Green coffee bean extract improves obesity by decreasing body fat in high-fat diet-induced obese mice. Asian Pacific Journal of Tropical Medicine. (2016) 9; 7: 635-643.

20. Shi H, Dong L, Bai Y, Zhao J, Zhang Y, Zhang L. Chlorogenic acid against carbon tetrachlorideinduced liver fibrosis in rats. Eur J Pharmacol. 2009;623 (1-3): 119-124.

21. Raafat, N., Aal, S.M.A., Abdo, F.K. and El Ghonaimy, N.M..Mesenchymal stem cells: in vivo therapeutic application ameliorates carbon tetrachloride induced liver fibrosis in rats. The international journal of biochemistry \& cell biology, 2015;68:109-118.

22. Shalaby, S.M., Amal, S., Abd-Allah, S.H., Selim, A.O., Selim, S.A., Gouda, Z.A., El Motteleb, D.M.A., Zanfaly, H.E., EL-Assar, H.M. and Abdelazim, S., Mesenchymal stromal cell injection protects against oxidative stress in Escherichia coli-induced acute lung injury in mice. Cytotherapy, 2014.16(6):764-775.

23. Bancroft J, Layton C. The Hematoxylin and eosin. In: Suvarna SK, Layton C and Bancroft JD (ed). Theory and Practice of histological techniques. 7th ed. Churchill Livingstone of El Sevier, Philadelphia: Ch. 10 and 11; 2013: 172-214.

24. Drury RA, Wallington EA. Carlton's histological techniques. 5th ed. Oxford: Oxford University Press. 1980.

25. Ramos-Vara JA, Kiupel M, Baszier T, Bliven L, Brodersen B, Chelack B. Suggested guidelines for immunohistochemical techniques in veterinary diagnostic laboratories.J Vet Diagn Invest.2008; 20: 393-413.

26. Abdou, A. G., Hammam, M. A., Farag, A. G. A., Farouk, S., Fawzy, M., Immunohistochemical expression of cyclinA in testicular biopsies of fertile and infertile men: correlation with the morphometry of seminiferous tubules. Andrologia, 2011.43(1), 57-64.

27. Field A. (2013). Discovering statistics using IBM SPSS statistics. Sage, New Delhi.

28. Lebda MA, Sadek KM, Abouzed TK, Tohamy HG, El-SayedYS.Melatonin mitigates thioacetamideinduced hepatic fibrosis via antioxidant activity and modulation of proinflammatory cytokines and fibrogenicgenes.Life Sci. 2018. 1;192:136-143.

29. Mujeeb M, Khan SA, Aeri V, Ali B Hepatoprotective activity of the ethanolic extract of FicuscaricaLinn. Leaves in carbon tetrachlorideinduced hepatotoxicity in rats. Iran J Pharm Res. 2011;10:301-6.

30. Hajovsky H, Hu G, Koen Y, Sarma D, Cui W, Moore DS, et al. Metabolism and toxicity of thioacetamide and thioacetamide S-oxide in rat hepatocytes. Chem Res Toxicol. 2012;25:1955-63.

31. Koen YM, Sarma D, Hajovsky H, Galeva NA, Williams TD, Staudinger JL, et al. Protein targets of thioacetamide metabolites in rat hepatocytes. Chem Res Toxicol. 2013;26:564-74.

32. Turkdogan MK, Agaoglu Z, Yener Z, Sekeroglu $\mathrm{R}$, Akkan HA, Avci ME. The role of antioxidant vitamins ( $\mathrm{C}$ and $\mathrm{E}$ ), selenium and Nigella sativa in the prevention of liver fibrosis and cirrhosis in rabbits: new hopes. Deutsche TierarztlicheWochenschrift. 2001;108:71-73

33. Saller R, Meier R, Brignoli R. The use of silymarin in the treatment of liver diseases.Drugs.2001; 61(14):2035-2063

34. Wei Z, Rutao H, Tulei T. Silymarin's Protective Effects and Possible Mechanisms on Alcoholic Fatty Liver for Rats. BiomolTher(Seoul). 2013; 21(4): 264-269.

35. Ahmad A, Pillai KK, Najmi AK, Ahmad SJ, Pal SN, Balani DK, et al. Evaluation of hepatoprotective potential of Jigrine post-treatment against thioacetamide induced hepatic damage. J Ethnopharmacol. 2002;79:35-41.

36. Post-White J, Ladas EJ, Kelly KM. Advances in the use of milk thistle (Silybummarianum). Integr. Cancer Ther.2007;6: 104-109.

37. Deep G, Agarwal R. Chemopreventive efficacy of silymarin in skin and prostate cancer. Integr. 
CancerTher. 2007;6: 130-145.

38. Sanchez GI, Jimenez EF, SauraCF.. In vitro antioxidant activity ofcoffees brewed using different procedures (Italian, espresso and filter)., Food Chem. 2005. 90: 133-139.

39. Al-Asmari AK, Abbasmanthiri R, Al-Elewi AM, Al-Omani S, Al-Asmary S, Al-Asmari SA, et al. Camel milk beneficial effects on treating gentamicin induced alterations in rats. J Toxicol. 2014;2014:917608.

40. Ramadan LA, Roushdy HM, Abu Senna GM, Amin NE, El-Deshw O. A Radioprotective effect of silymarin against radiation induced hepatotoxicity. Pharmacol Res. 2002; 45:447-54.

41. Mona G Amer, Nehad F Mazen, and Ahmed M Mohamed; Caffeine intake decreases oxidative stress and inflammatory biomarkers in experimental liver diseases induced by thioacetamide: Biochemical and histological study,Int J ImmunopatholPharmacol. 2017; 30 (1): $13-24$.

42. Chan ES, Montesinos MC, Fernandez P, Desai A, Delano DL, Yee H et al.AdenosineA(2A) receptors play a role in the pathogenesis of hepatic cirrhosis. Br J Pharmacol 2006;148:1144-55.

43. Yun-Chen T, Jung-Chun L, Chuan-Sung C, TaiHung H, Chih-Yang H, Wen-Te C, et al. Esculetin Ameliorates Carbon Tetrachloride-Mediated Hepatic Apoptosis in Rats. Int J Mol Sci. 2011;3: 119-124.
44. Abdullah A, Muhammed İC. Milk thistle impedes the development of carbontetrachloride-induced liver damage in rats through suppression of bcl2 and regulating caspase pathway. Life Sciences. 2014;117:13-18

45. Hunyadi A, Martins A, Hsieh TJ,Seres A, Zupkó I. Chlorogenic acid and rutin play a major role in the in vivo anti-diabetic activity of Morus alba leaf extract on type II diabetic rats. PLoS One. 2012;7(11):e50619.

46. Oku H, Ogawa $\mathrm{Y}$, IwaokaE, IshiguroK. Allergypreventive effects of chlorogenic acid and iridoid derivatives from flower buds of Lonicera japonica. Biol Pharm Bull. 2011;34(8):1330-1333.

47. Gavrilova V, Kajdzanoska M, GjamovskiV,Stefova M. Separation, characterization and quantification of phenolic compounds in blueberries and red and black currants by HPLC-DAD-ESI-MSn . J Agric Food Chem. 2011; 59(8):4009-4018.

48. del Rio D, Stalmach A, Calani L, Crozier A. Bioavailability of coffee chlorogenic acids and green tea flavan-3-ols. Nutrients.2010;2(8):820-833.

49. dos Santos MD, Almeida MC, Lopes NP, Norberto PL, Glória EP. Evaluation of the anti-inflammatory, analgesic and antipyretic activities of the natural polyphenol chlorogenicacid.Biol Pharm Bull. 2006;29(11):2236-2240. 


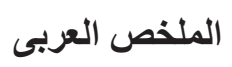

تأثير السيليمارين مقابل السيليمارين ومستخلص البن الأخضر على إصابة الكبد

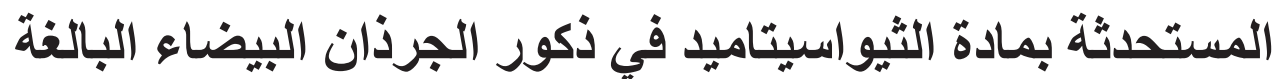

(دراسة هستولوجية وهستوكميائية مناعية )

\section{سارة محمد محمود عبد العال، هناء سعيد السيد موسى، سماح محمد أحمد}

قسم الهستولوجيا وبيولوجيا الخلية_كلية|لطب- جامعة/الزقازيق.

الخلفية:يعتبر الثيو أسيتاميد من العوامل السامة للكبد فهو يستخدم على نطاق واسع لإحداث سمية الكبد في حيوانات التجارب. تم إثبات خصائص السيليمارين الوقائيه لسمية الكبد سابقا. تعتبر القهوة أكثر المشروبات شعبية في العالم. استهلاك القهوة له فو ائد عديدة على الصحة بشكل عام ، وصحة الكبد على وجه الخصوص، لذلك أجريت الدراسة الحالية لتقييم الدور المحتمل لإضافة مستخلص البن الأخضر إلى سيليمارين في تحسين إصابة الكبد المستحدثة بالثيو أسيتاميد في الجرذان.

المواد والطرق: تم تقسيم ستة وثلاثين جرذ من ذكور الجرذان البيضاء البالغة إلى أربع مجموعات. المجموعة الأولى(المجموعة الضابطة)، المجموعة الثانية (المجموعة المعالجة بالثيو أسيتاميد)المجموعة الثالثة ) المجموعة المعالجة بالسيليمارين) و المجموعة الرابعة( المعالجة بالسيليمارين ومستخلص القهوة الخضر اء.(في نهاية التجربة أجرى التحليل الكيميائي الحيوي لتقييم وظائف الكبد (مصل ألانين تر انسامنيز و اسبرتات تر انسامنيز )كما قيست أيضا إنزيمات مضادة للأكسدة ومقايسة الجلو تاثيون و اجربت در اسة هستولوجية باستخدام صبغة الهيماتوكسين والإيوسين و صبغه الماسون ثلاثية اللون و استخدمت صبغة هستوكميائية مناعية للكثف عن كاسباس 3 و تم إجراء تحاليل مورفومترية للصور و إحصائية للنتائج. النتائج: لقد أظهرت وظائف الكبد لجرذان المجموعة الثانية تدهورًا كبيرًا في الاستجابة للثيو أسيتاميد بالإضافة إلى التغير ات النسيجية الهامة في فصوص الكبد و المناطق البابية التي تحسنت بشكل طفيف في المجمو عة الثالثة وتميل إلى بلى لإلى إلى أن تكون طبيعية في جرذان المجموعة الر ابعة. الخلاصة: نستخلص من هذا البحث أن إضافة مستخلص البن الأخضر إلى السيليمارين يحسن النأثير العلاجي للسيليمارين في علاج الإصابة الكبدية المستحدثة تجريبياً بو اسطة الثيو اسيتاميد في الجرذان. 